\title{
DESIGN AND FABRICATION OF CONCRETE- REINFORCED FLOATING PLATFORM FOR CANAL AND RIVER-SHORE PROTECTION
}

\author{
Kreetha Somkeattikul, Chinnathan Areeprasert*, Prysathyrd Sarabhorn, and Thanya \\ Kiatiwat
}

Department of Mechanical Engineering, Faculty of Engineering, Kasetsart University, Bangkok, Thailand, e-mail: fengcta@ku.ac.th

Received Date: September 22, 2020; Revised Date: April 26, 2021; Acceptance Date: August 13, 2021

\begin{abstract}
Erosion of canal and river-shore causes problems on agriculture activities and soil environment. This paper devotes to develop a floating platform to protect the shores. A concrete-reinforced floating platform was designed and fabricated in this study. Mechanical simulation was performed to ensure the design viability. The concrete-reinforced floating platform consists of three main parts: (1) steel structure, (2) foam-cement material, and (3) connecting joints. The dimension of the cement foam floating platform is $1.2 \mathrm{~m}$ in width, $3 \mathrm{~m}$ in length and $0.4 \mathrm{~m}$ in thickness. The cement used in this research is resistant to corrosion of sulfate and chloride from saltwater. Foam with density of $12 \mathrm{~kg} / \mathrm{m}^{3}$ is mixed with concrete matrix so that the floating platform can float $60 \%$ or $0.16 \mathrm{~m}$ above the water surface. The foam cement material has the maximum compression stress of $1,951 \mathrm{~kg} \pm 266.59 \mathrm{~kg}$ for the material density of $427.30 \mathrm{~kg} / \mathrm{m}^{3} \pm 19.30 \mathrm{~kg} / \mathrm{m}^{3}$. The connecting joint part has the ultimate tensile load of $1,564 \mathrm{~kg}$. The assemble floating platform has the compressive stress of $543.33 \mathrm{~kg} / \mathrm{m}^{2}$ with the maximum vertical deformation of samples of $1 \mathrm{~mm}$ under the distribution load of 1,571 over the samples. Finally, from simulation with data from the material testing, the designed floating platform had a safety factor 3.46 which was higher than the design criteria of 3 .
\end{abstract}

Keywords: Concrete-reinforced, Floating platform, Mechanical design, Simulation

\section{Introduction}

Today, many countries around the world suffer from the loss of riverbank landings every year. In Southeast Asia, there are several studies on the causes and effects of loss of coastal land. Study of soil bank erosion in ASEAN countries such as Vietnam, land bank losses are caused by wave erosion. These waves caused the development of water transport, resulting in a much greater expansion of water traffic by boats. In addition, bank erosion is caused by climate change, as well as various human livelihood activities that alter the climate and natural environment [1]. Currently, Thailand has many soil erosion problems about the canal and natural river banks. In which these banks were inhabited, agriculture, and natural attractions areas. The erosion of the banks of the canals and rivers has a profound effect on the lives of people living along the waterfront. The erosion of the river banks also has a great impact on the agriculture of farmers in Thailand, resulting in the loss of fertile agricultural land, causing shallow canals and loss of ability to drain the water of canals or river [2]. The problem of soil bank erosion may be the result of natural water currents or waves caused by water traffic by boats or water vehicles 
that are increasing today, including flooding situations [3]. Riverbank erosion and topsoil loss due to developments in agriculture, water transport, and current climate change. If the data is not collected and studied seriously it can result in irreversible damage to soil resources [4].

The erosion of the river and canal banks, at present, the problem of reducing soil bank erosion has been solved by creating a permanent dam to protect the strength of the water currents and reduce the wave strength caused by water traffic and natural water currents. In some countries, the erosion of water banks is reduced by planting cover crops such as Vetiver Grass or by using other plant species to protect against the waves of tidal currents [5]. Researchers from various countries have created Groyne to block, slow down and change the direction of the current so that the current does not have the speed and direction of the flow, eroding and destroying the riverbank soil directly, reducing the loss of bank soil. Groynes are designed and used to prevent the erosion of river banks caused by currents and flow directions in many countries around the world. Most groynes are designed and installed on the curved banks of the river and are perpendicular to or obstructing the direction of the current flow [6]. Researchers have studied and collected data on the prevention of erosion and erosion of river banks and canals. Based on the results of this study and compilation, the design of floating platforms for protection against currents and waves arising from the movement of boats in rivers and canals is suitable for installation and ease of use. Moreover, floating platforms can float according to the water level in rivers and canals because the water level in rivers and canals is constantly changing. Therefore, the floating platform must be designed to suit the characteristics of the river and be strong enough to withstand the force of the water waves caused by the movement of the boat.

Currently, floating platforms have various designs. A floating platform was designed using cement or concrete to create a floating platform. The density of the floating platform must be less than the density of the water. For example, a floating platform design by outer shell and hollow inner shall with air or foam inside to make it a density lower than water [7]. The floating platform made of whole concrete blocks must be designed to be less dense than water so a very small density material is required. Thus, cement is often mixed with very low-density materials such as EPS foam to make the floating platform able to float above the water level and be strong enough to withstand the load that acting on the floating platform [8]. Most of the load or force comes from the force of the water flow and the waves that hitting the floating platform. The waves may come from the flow of the tides or the movement of the boats. Analysis of the forces that act on a floating platform is analyzed in different ways depending on the behavior of water resources and the environment to install a floating platform [9]. M.S. Kirkgöz has analyzed and calculated the load or the force of the waves exerted on a floating platform or a coastal area. The results of the experiment were performed on variables such as the depth of the water level affecting the force of the wave [10]. H. E. Dempster designed the concrete floating structure by designing the floating platform to float on water with an air gap inside of the floating platform that wrapped in mixed concrete with plastic to make the concrete have a lower density. He designed air gaps inside the floating platform, the floating platform's density is less than the water density, thus enabling the floating platform to float on water [11]. However, limited works have been done on floating platform for rivers and canals to prevent erosion of the soil bank, 
reduce the loss of topsoil and farmland. Because the force exerting to the rivers and canals are different, the design of the floating platform shall be optimized.

This work focuses on the design and fabrication of a concrete-reinforced floating platform for rivers and canals application. Firstly, the design was done by calculating the forces exerted on the floating platforms by the waves arising from the movement of boats in rivers and canals for the design of steel structures on the inside of the floating platforms which must be able to support the force of the wave not exceeding 14,000 N. The proportions of the foam cement mixture were calculated to have a strength and sufficient density for float ability above the water surface $40 \%$. So the design and calculation of the mixing ratio of the foam cement and the structural steel must have a total density less than $600 \mathrm{~kg} / \mathrm{m}^{3}$. Secondly, the flatform was fabricated steel structure for testing the tensile strength of the floating platform connecting joint, mixing, and casting foam cement cylinders for testing the compressive strength of foam cement materials, and built a floating platform to test the compression and collapse of the floating platform. Then, the samples of each part were subjected to mechanical testing. Finally, the simulation results were compared with the experiment.

\section{Materials and Methods}

\section{Raw Material}

\section{Steel Structure}

Construction steel was used for the internal structure of the floating platform, which is designed to be able to withstand loads as required. It has sufficient mechanical properties for structural design. The weight of the steel structure affects the total density and buoyancy force of the floating platform. The structural steel properties from the manufacturer (Pacific Pipe Public Co., Ltd.) are shown in Table 1.

Table 1. Mechanical Properties of Steel Structure

\begin{tabular}{ccc}
\hline Property & Value & Unit \\
\hline Yield strength & 400 & $\mathrm{MPa}$ \\
Tensile strength & 560 & $\mathrm{MPa}$ \\
Elastic modulus & 200 & $\mathrm{GPa}$ \\
Poisson's ratio & 0.3 & - \\
Mass density & 7,850 & $\mathrm{~kg} / \mathrm{m}^{3}$ \\
\hline
\end{tabular}

For reinforcing bar steel using a steel rod SD50 with a diameter of $12 \mathrm{~mm}$ which has a yield strength of $490 \mathrm{Mpa}$. This data is based on the manufacturer (TATA steel Thailand), subject to the tisi 24-2559 standards.

\section{Marine-dry Concrete}

A marine-dry concrete with sulfate resistance is suitable for the marine area applications. It has high sulfate and chloride salt. This work used marine-dry concrete sulfate M403S which has good sulfate resistance. Because the floating platform must be able to float on both freshwater 
and saltwater, the marine-dry concrete has a bulk density of about $1,400 \mathrm{~kg} / \mathrm{m}^{3}$ (manufacturer data: TPI Polene Public Co., Ltd.) that is used for calculating the mixing raw materials to build the cement floating platform.

\section{Polystyrene Foam}

Polystyrene foam was utilized as a material for mixing with cement. It is responsible for creating porous in the cement platform since it will be expanded during the production process. Expanded polystyrene (EPS) reduces the weight of the cement platform in its original volume. Therefore, the density of the cement platform is lower. The Properties of EPS foam used in this research is from the manufacturer (Cebau Industries Co., Ltd.) as presented in Table 2.

Table 2. Physical and Mechanical Properties of Expanded Polystyrene (EPS)

\begin{tabular}{ccc}
\hline Property & Value & Unit \\
\hline Density & 12 & $\mathrm{~kg} / \mathrm{m}^{3}$ \\
Compressive strength & 0.09 & $\mathrm{MPa}$ \\
Flexural strength & 0.21 & $\mathrm{MPa}$ \\
Water Absorption & 4 & $\%$ by volume \\
Bead Size & $3-5$ & $\mathrm{~mm}$ \\
\hline
\end{tabular}

\section{Design and Calculation}

Design and calculation of foam cement mix formulas are as follows: the dimensions of the design are $1.2 \mathrm{~m}$ width, $3 \mathrm{~m}$ length, $0.4 \mathrm{~m}$ thickness, equivalent to a volume of $1.44 \mathrm{~m}^{3}$. The floating platform must be able to float $40 \%$ above the surface, which is equal to $0.16 \mathrm{~m}$. Therefore, the design and calculation of the mixing ratio of the foam cement and the structural steel must have a total density less than $600 \mathrm{~kg} / \mathrm{m}^{3}$. Calculation of the weight of the material in the mixture must have the total weight less than $864 \mathrm{~kg}$ as shown in Table 3.

\section{Table 3. Mixing Composition of the Material}

\begin{tabular}{cccccccccc}
\hline \multicolumn{2}{c}{ Cement } & \multicolumn{2}{c}{ Water } & EPS Foam & Steel & Other & Total & Total \\
$\begin{array}{c}\text { Volume } \\
\left(\mathrm{m}^{3}\right)\end{array}$ & $\begin{array}{c}\text { weight } \\
(\mathrm{kg})\end{array}$ & $\begin{array}{c}\text { Volume } \\
\left(\mathrm{m}^{3}\right)\end{array}$ & $\begin{array}{c}\text { weight } \\
(\mathrm{kg})\end{array}$ & $\begin{array}{c}\text { Volume } \\
\left(\mathrm{m}^{3}\right)\end{array}$ & $\begin{array}{c}\text { weight } \\
(\mathrm{kg})\end{array}$ & $\begin{array}{c}\text { weight } \\
(\mathrm{kg})\end{array}$ & $\begin{array}{c}\text { Weight } \\
(\mathrm{kg})\end{array}$ & $\begin{array}{c}\text { Weight } \\
(\mathrm{kg})\end{array}$ & $\begin{array}{c}\text { Density } \\
\left(\mathrm{kg} / \mathrm{m}^{3}\right)\end{array}$ \\
\hline 0.36 & 501 & 0.08 & 80.064 & 1.00 & 12.19 & 240 & 30 & 864 & 599.3 \\
\hline
\end{tabular}

\section{Cement-foam Mixture}

The designed cement foam mixture has the density not exceeding $600 \mathrm{~kg} / \mathrm{m}^{3}$. The $\mathrm{w} / \mathrm{c}$ ratio is 0.24 with the proportion of the composite material, which is cement $25 \%$ by volume, water $6 \%$ by volume, and foam $69 \%$ by volume. The total weight of the floating platform does not exceed $864 \mathrm{~kg}$ consisting of a $593 \mathrm{~kg}$ cement-foam composite. Steel structures have a weight not exceeding $240 \mathrm{~kg}$ and other materials has a weight lower than $30 \mathrm{~kg}$. The proportion of the mixture makes the floating platform that has a density of $599.3 \mathrm{~kg} / \mathrm{m}^{3}$. 


\section{Steel Structure}

The weight of the designed steel structure must not exceed $240 \mathrm{~kg}$ with dimension as follows: $1.2 \mathrm{~m}$ width, $3 \mathrm{~m}$ length, and $0.4 \mathrm{~m}$ thickness. When casting foam cement, the density of the floating platform does not exceed $600 \mathrm{~kg} / \mathrm{m}^{3}$, which allows the floating platform to float as specified. The internal steel structure model is shown in Figure 1.

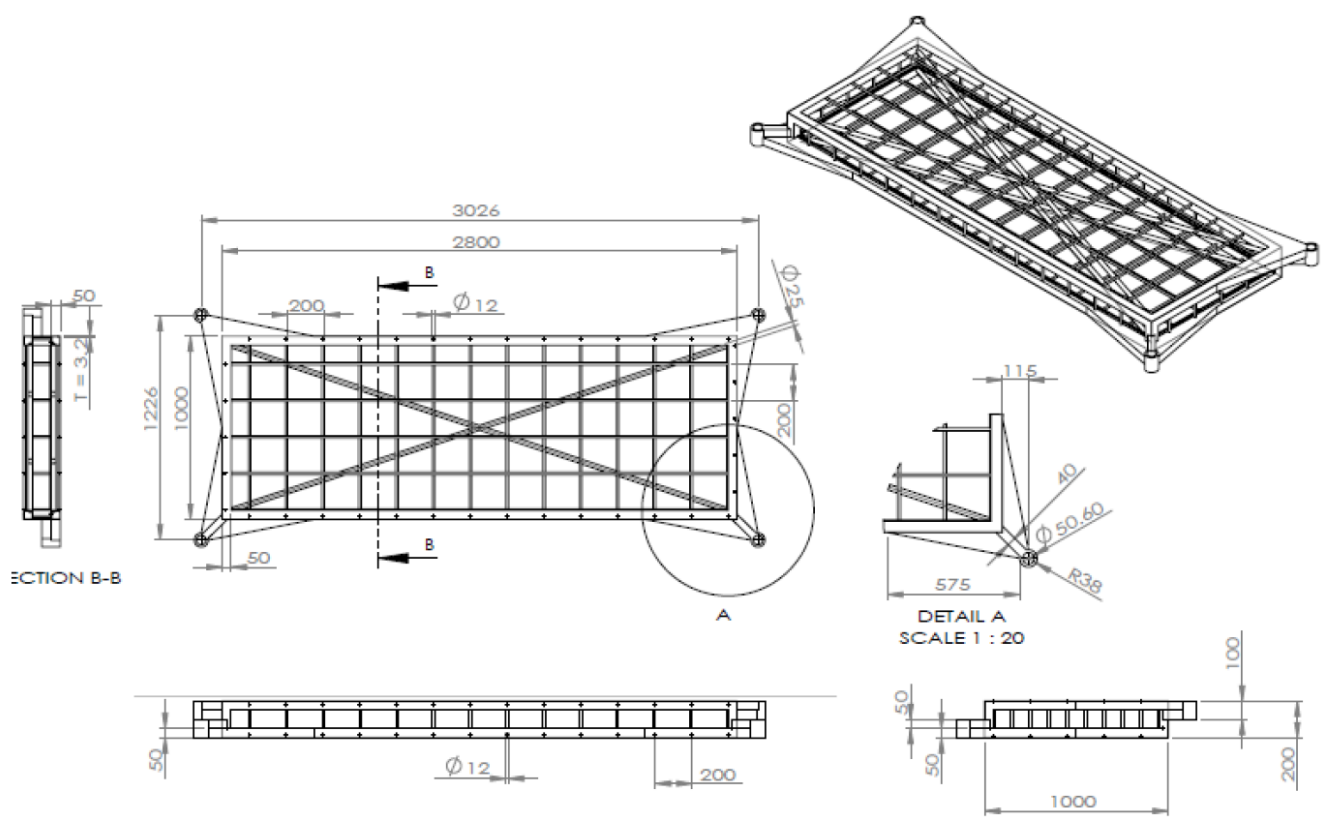

Figure 1. Design of steel structure

\section{Composite Material Fabrication}

\section{The Procedure of Mixing Cement Foam}

The process of mixing is briefly described in this subsection. The weight of each composition follows the mixing composition ratio in Table 3. First, water was added in the concrete mixing machine. Then, EPS foam was fed and the mixing machine started turning and keep mixing for $1 \mathrm{~min}$. Secondly, cement was added and the mixer was kept turning for $5 \mathrm{~min}$. Then, the mixer was halted to ensure that the mixture was mingled thoroughly by manually scraping out the cement foam attached to the inner surface of the machine. After that, the machine was kept mixing for another 5-min. Finally, the mixture was injected into the mold, compress, and naturally dry for $24 \mathrm{~h}$. The product was removed from the mold and cure in water for $28 \mathrm{~d}$.

\section{Fabrication of Steel Structures and Floating Platforms}

The internal steel structure of the floating platform was fabricated from a structural steel by welding according to the production drawing as shown in Figure 1. To fabricate the steel structure, the steel was cut to the size according to the design and then electrically welded by high tensile strength (490 MPa) Familiarc LB-5 2 electrodes with the welding parameters including electrode diameter 3.2 mm, electric current 100-170 A, and welding speed 40-60 $\mathrm{cm} / \mathrm{min}$. After that, the cement foam was mixed according to section 2.3.1 and then cast to cover 
the steel structure in a rectangular shape with the dimension as follows: $1.2 \mathrm{~m}$ in width, $3 \mathrm{~m}$ in length and $0.4 \mathrm{~m}$ in thickness. After $24 \mathrm{~h}$, the mold was removed and the floating platform was cured with water for $28 \mathrm{~d}$.

\section{Mechanical Property Testing}

The foamed concrete specimen was subjected to the compressive test using a hydraulic pressure testing machine shown in Figure 2 according to the ASTM C39 Standard Test Method for Compressive Strength of Cylindrical Concrete Specimens. The load was continuously applied to the foamed concrete at the rate of $4 \mathrm{~mm} / \mathrm{min}$ until fracture or damage was detected. The displacement of the compressive testing can be viewed from the measuring instrument on the tester screen and the test result curve. The compressive test was triplicated to ensure the reproducibility of the results. The dimension of cylindrical foamed concrete was $15 \mathrm{~cm}$ diameter and $30 \mathrm{~cm}$ height.

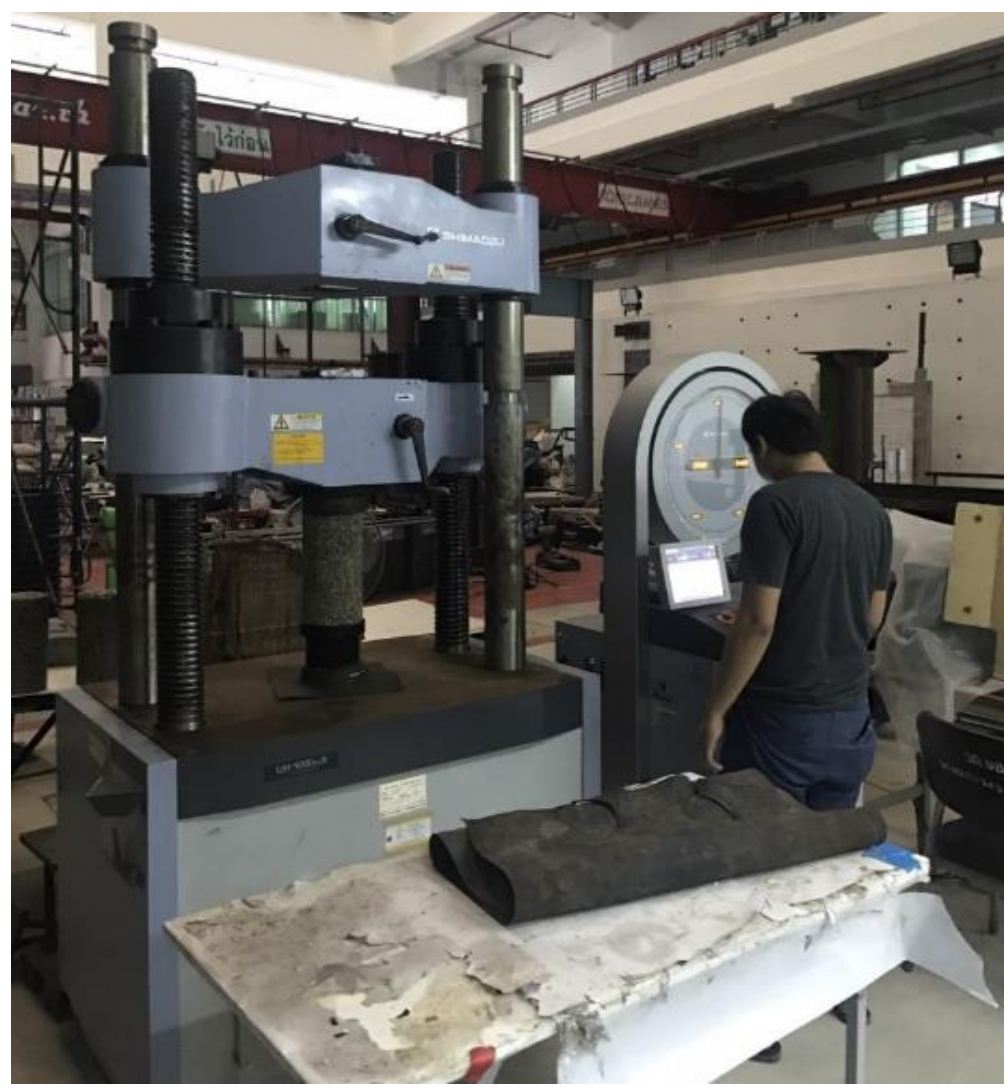

Figure 2. Hydraulic pressure testing machine.

\section{Simulation}

Strength of the floating platform and its joints was analyzed by Solidworks simulation program and compared with the experiment results. The strength analysis utilized the finite element method which divided the object into small parts called elements. To precisely analyze the strength of the work piece, this analysis is in the elastic zone phase, so Hook's law analysis is 
applicable. The normal stress causes normal strain while shear stress causes shear strain. The normal strains produce dilatations while shear strain produces angle deformations. The corresponding mathematical model [12] can be expressed as follows Equation (1)-(3).

$$
\varepsilon_{x}=\left(d x+\frac{\partial u_{x}}{\partial x} d x-d x\right) / d x
$$

And the normal strains in the $y$ and z-direction are

$$
\begin{gathered}
\varepsilon_{y}=\frac{\partial u_{y}}{\partial y} \\
\varepsilon_{z}=\frac{\partial u_{z}}{\partial z}
\end{gathered}
$$

The shear strain value specified as $\gamma_{x y}$, expresses the transformation in the square angle amongst $\mathrm{AC}$ and $\mathrm{AB}$ as shown in [12] and is equal to $\gamma_{x y}=\alpha+\beta$. Further, based on the geometry, the following can be written as Equation (4)-(6).

$$
\begin{gathered}
\gamma_{x y}=\alpha+\beta=\frac{\partial u_{y}}{\partial x}+\frac{\partial u_{x}}{\partial y}=\gamma_{y x} \\
\gamma_{y z}=\frac{\partial u_{y}}{\partial z}+\frac{\partial u_{z}}{\partial y}=\gamma_{z y} \\
\gamma_{x z}=\frac{\partial u_{x}}{\partial z}+\frac{\partial u_{z}}{\partial x}=\gamma_{z x}
\end{gathered}
$$

The normal stresses are identified as principal stresses $\left(\mathrm{P} 1\left(\sigma_{1}\right), \mathrm{P} 2\left(\sigma_{2}\right)\right.$ and $\left.\mathrm{P} 3\left(\sigma_{3}\right)\right)$ and are linked to the minimum and maximum stretches. The corresponding strains are known as principal strains $\left(\mathrm{E} 1\left(\varepsilon_{1}\right), \mathrm{E} 2\left(\varepsilon_{2}\right)\right.$ and E3( $\left.\left.\varepsilon_{3}\right)\right)$. Equivalent stress (von Mises stress) is frequently used in the design work because it permits any arbitrary three-dimensional stress state characterized by a single positive stress value. Equivalent stress is part of the maximum equivalent stress failure theory used to forecast yielding in a ductile material. Equivalent stress is correlated to the principal stresses by the Equation (7).

$$
\sigma_{e}=\sqrt{\frac{\left(\sigma_{1}-\sigma_{2}\right)^{2}+\left(\sigma_{2}-\sigma_{3}\right)^{2}+\left(\sigma_{3}-\sigma_{1}\right)^{2}}{2}}
$$


And the equivalent strain $\varepsilon_{e}$ (Equivalent strain) is calculated as Equation (8).

$$
\varepsilon_{e}=\frac{1}{1+v} \sqrt{\frac{\left(\varepsilon_{1}-\varepsilon_{2}\right)^{2}+\left(\varepsilon_{2}-\varepsilon_{3}\right)^{2}+\left(\varepsilon_{3}-\varepsilon_{1}\right)^{2}}{2}}, \text { where } v \text { is Poisson's ratio }
$$

The maximum von mises stress criterion is appropriate for ductile materials. It is based on shearenergy theory, which states that a ductile material starts to yield at a position. At that point, von mises stress $\left(\sigma_{\text {von Mises }}=\sqrt{\frac{\left(\sigma_{1}-\sigma_{2}\right)^{2}+\left(\sigma_{2}-\sigma_{3}\right)^{2}+\left(\sigma_{3}-\sigma_{1}\right)^{2}}{2}}\right.$ ) becomes equal to the stress limit. Generally, the yield strength is used as the stress limit and relate $\sigma_{\text {von Mises }}$ to $\sigma_{\text {limit }}$. The factor of safety at a position is calculated as Equation (9).

$$
\text { Factor of Safety }(\mathrm{FoS})=\frac{\sigma_{\text {limit }}}{\sigma_{\text {von Mises }}}
$$

In the case of pure shear, von Mises stress can be expressed as $\sigma_{\text {von Mises }}=\sqrt{3} \tau$ Hence, failure arises when $\tau_{\max }=0.577 \sigma_{\text {yield }}$.

This research has analyzed the strength compared with the experimental results in two parts as follows:

\section{Tensile Strength of The Connecting Joint}

The strength test of the connecting joint was tested by pulling the connecting joint until it was damaged. Therefore, $3 \mathrm{D}$ modeling of the connecting joint has been made using a Solidworks simulation program and determined the structural steel materials with mechanical properties as in Table 1. Then, the fixture position was determined based on the actual test characteristics. Meshing of a part with solid elements was done by using linear tetrahedral elements because the workpiece has a straight shape. To obtain an accurate result, strength analysis of all 3D models uses the h-adaptive method for convergence of result which automatically reduces mesh size in areas where the calculated error is high and the target accuracy is $98 \%$. For the connecting joint, the result of strength analysis has numbers of elements were 31,370 elements for $98 \%$ accuracy. The fixture position and elements are shown in Figure 3A.

\section{Compressive and Deformation of Foam-cement Floating Platform}

The compressive strength testing of the cement foam floating platform was tested by a distributed load on the cross-sectional area of the floating platform. The cross-sectional area is $1.2 \mathrm{~m}$ wide and $3.0 \mathrm{~m}$ long. The test was done by pressing the object until the deformation displacement occurs according to the design requirements which is equal to $1 \mathrm{~mm}$ without breaking or separating the material of the floating platform. The floating platform analysis was based on the actual test data. Solid elements were determined as the linear tetrahedral element because the workpiece is straight. In this simulation, the numbers of elements were 50,549 elements. Meshed floating platform is presented in Figure 3B. 


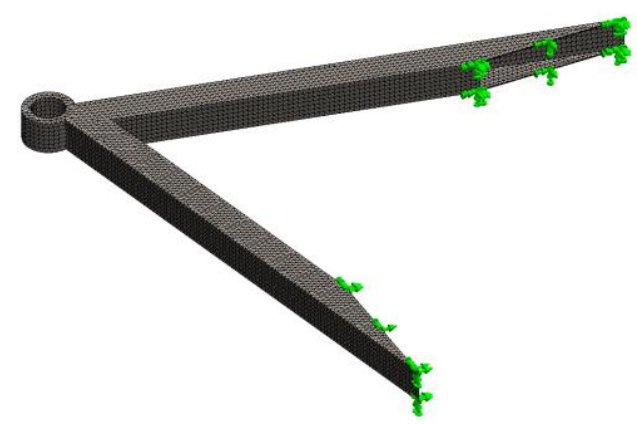

(A)

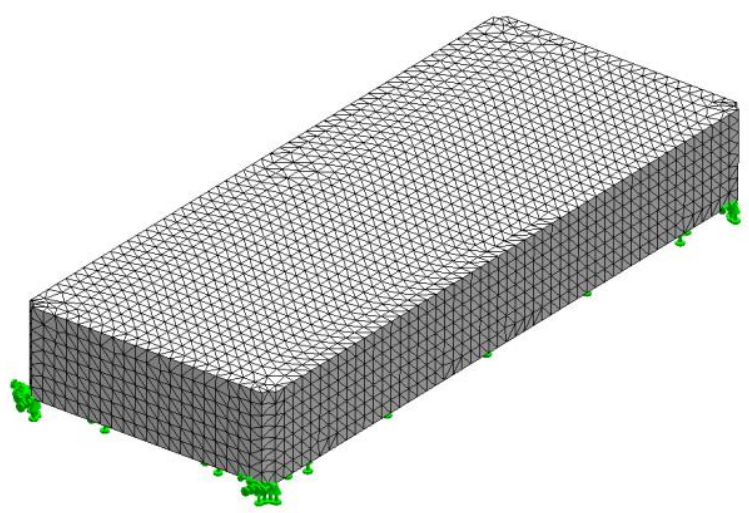

(B)

Figure 3. Meshing and fixture position of (A) connecting joint; (B) Cement foam floating platform

\section{Results and Discussion}

\section{Floating Platform Product Overall}

The cement foam floating platform is designed to be $1.2 \mathrm{~m}$ in width, $3 \mathrm{~m}$ in length and $0.4 \mathrm{~m}$ in thickness. The steel structure shown in Figure 4A is responsible for the force from the various loads that are applied to the floating platform and also has the function for carrying the load from the attachment points from other parts of the structure. After that, overlay the steel structure with cement foam mixture. P.E. Smith said that the most common approach is to protect the steel with a high-quality concrete, thus prolonging the ingress of the chlorides such that the desired service life is obtained before there is sufficient chloride concentration at the steel location to initiate corrosion. Therefore, it must be designed using cement that covers the steel structure with low penetrability and sufficient thickness of such cover concrete provides this protection. The penetrability and thickness of the cover concrete will be the primary factors in determining whether the service life of a structure will be [13]. M. Thomas said that the cement used for marine structural design must have properties as chloride resistance, freeze-thaw 
resistance, resistance to sulfates and other chemical attacks, abrasion resistance, and alkalizeaggregate reaction [14]. Therefore, the cement used in this research is resistant to corrosion of sulfate and chloride from saltwater mixed with foam with a density is approximately $12 \mathrm{~kg} / \mathrm{m}^{3}$ so that the floating platform can float $60 \%$ or above the water surface, approximately 0.16 meters, which the design must circumscribe and control the design of the cement foam platform and steel structure. Nyal Jennings calculated and designed a floating of the low-density concrete barrier, with foam and fiber-reinforced concrete densities without reinforcement structures lower than the density of the water. The composite material has a density of around $450 \mathrm{~kg} / \mathrm{m}^{3}$ so that the floating platform can float in the water [15]. From the mixing composition of materials in Table 3 which has the density of foam-cement specimens (Figure 4B) as 432.8 $\mathrm{kg} / \mathrm{m}^{3}$. Sergii O. Kroviakov researched and tested the lightweight concrete for floating structures and specified the density of cement composition with reinforced steel structure as $500-600 \mathrm{~kg} / \mathrm{m}^{3}$ [16]. Therefore, this research designed the cement foam floating platform and steel structure with total weight is not more than $864 \mathrm{~kg}$, which makes the floating platform density is 600 $\mathrm{kg} / \mathrm{m}^{3}$ as shown in Figure $4 \mathrm{C}$.

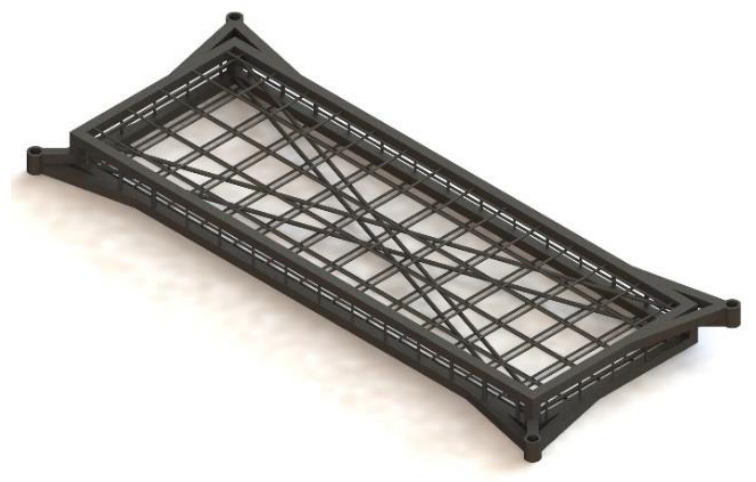

(A)

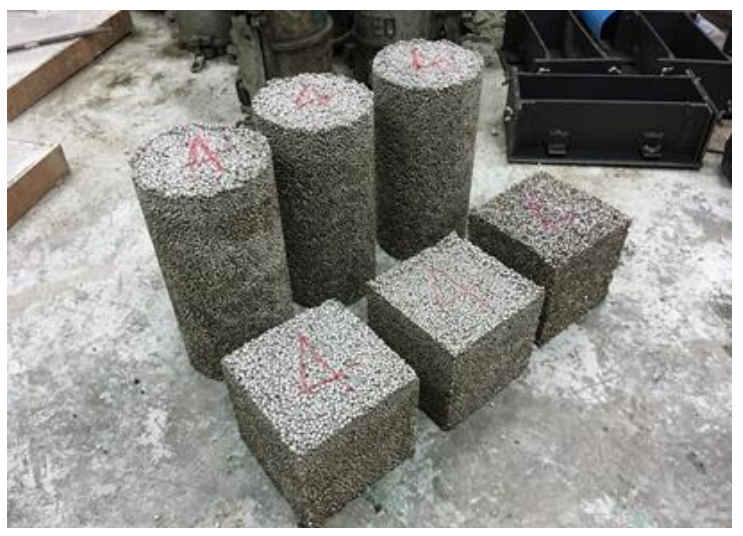

(B)

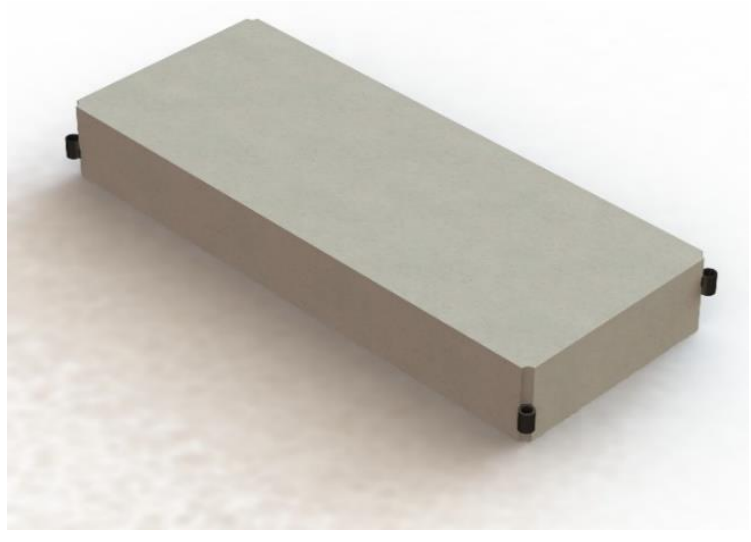

(C)

Figure 4. (A) Steel structure; (B) Composite concrete; (C) Floating platform 


\section{Floatability of The Floating Platform}

The floating test on the water surface of the cement foam floating platform by constructing the cement foam floating platform with internal steel structure to test the floating of the foam cement floating platform in the amount of 3 samples. They floated in the water with a density of about $1,023 \mathrm{~kg} / \mathrm{m}^{3}$, as shown in Figure 5. After that, the distance of the top surface of the floating platform to the water surface was measured. The floating test results of the cement foam floating platform are shown in Table 4.

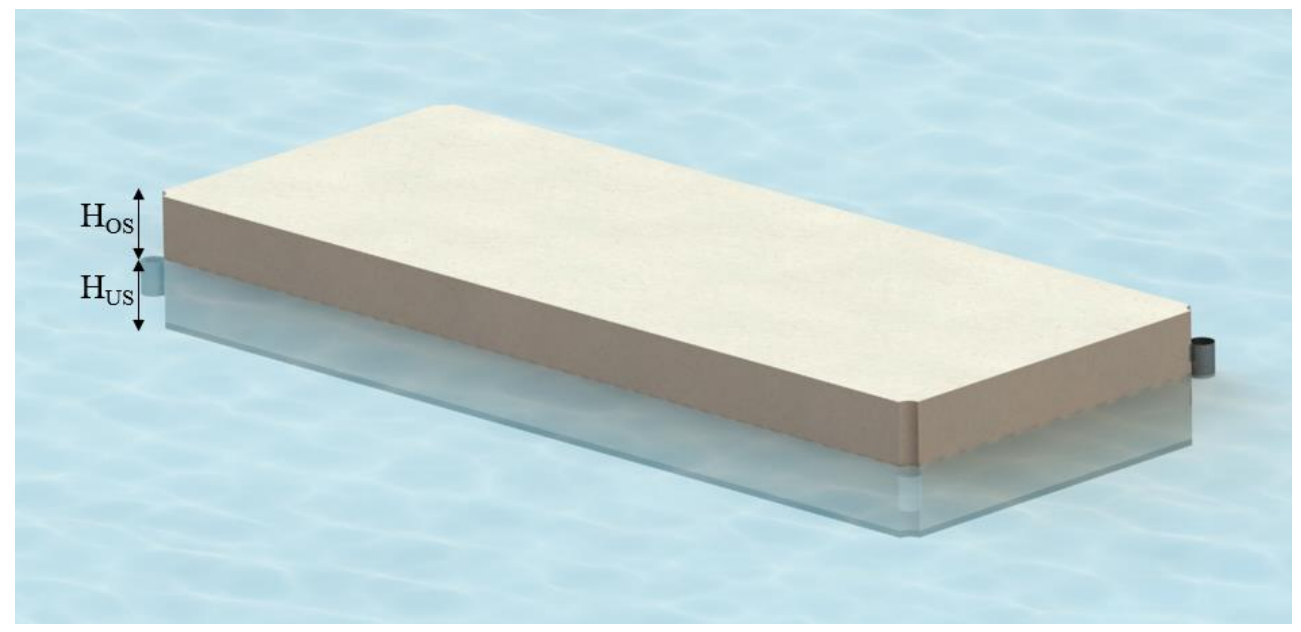

Figure 5. Floating test of the floating platform.

Table 4. Floating Test Result of the Floating Platform

\begin{tabular}{lcccc}
\hline \multicolumn{1}{c}{ Item } & $\mathbf{1}$ & $\mathbf{2}$ & $\mathbf{3}$ & Average \\
\hline $\begin{array}{l}\text { Weight of floating platform } \\
(\mathrm{kg})\end{array}$ & 795 & 742 & 774 & 770.3 \\
$\begin{array}{l}\text { Dimension of floating } \\
\text { platform; }\end{array}$ & $\begin{array}{c}1.22 \times 3.01 \times \\
0.39\end{array}$ & $\begin{array}{c}1.19 \times 2.98 \times \\
0.39\end{array}$ & $\begin{array}{c}1.2 \times 3.03 \times \\
0.4\end{array}$ & $\begin{array}{c}1.2 \times 3.0 \times \\
0.393\end{array}$ \\
$\begin{array}{l}\mathrm{W} \times \mathrm{L} \mathrm{x} \mathrm{H} \mathrm{(m)} \\
\begin{array}{l}\text { Volume of floating platform } \\
\left(\mathrm{m}^{3}\right)\end{array}\end{array}$ & 1.432 & 1.383 & 1.454 & 1.423 \\
$\begin{array}{l}\text { Floating distance level; Hos } \\
(\mathrm{m})\end{array}$ & 0.183 & 0.190 & 0.192 & 0.188 \\
$\begin{array}{l}\text { Buoyancy force (N) } \\
\text { Floating percentage (\%) }\end{array}$ & $7,999.81$ & $7,731.02$ & $7,670.64$ & $7,800.49$ \\
\hline
\end{tabular}

The calculated weight of the foam cement platform is $765 \mathrm{~kg}$, consisting of the weight of foam cement $593 \mathrm{~kg}$ and the weight of the internal steel structure is $172 \mathrm{~kg}$ and the volume is $1.44 \mathrm{~m} 3$. From the design and calculation, the floating platform has a buoyancy distance above 
the water surface (Hos) is equal to 0.192 meters, a buoyancy force equal to $7655.16 \mathrm{~N}$, representing a floating percentage equal to $48.07 \%$. The floating test results of the floating platform compared with the results of the design are deviation was $2.06 \%$.

\section{Mechanical Strength of The Products}

\section{Compressive Test of The Foam-cement Product Sample}

The testing of foam-cement mechanical properties can be tested by compression testing of composite materials following the ASTM C39 standard test method for compressive strength of cylindrical concrete specimens. The testing sample is $15 \mathrm{~cm}$ in diameter and $30 \mathrm{~cm}$ in length. The proportion of foam cement mixture consists of $6 \%$ water, $69 \%$ foam, and $25 \%$ cement by volume. To make the sample amount 3 pieces and take 28 days for curing, were tested by the hydraulic compression testing machine. Fang Yonghao et al. performed the investigation on the relationship between the compressive strength and air-void structure of foamed concrete and found that if the amount of air-void in cement foam composite increases, it will also reduce compressive strength. [17]. Helmut Weigler et al. studied about structural lightweight aggregate concrete with reduce density. The results also showed that compressive values also decreased [7]. The compression testing results ordered from the lowest density sample to the highest density sample are shown in Table 5. Averagely, the maximum compression stress was about $1,951 \mathrm{~kg} \pm 266.59 \mathrm{~kg}$ for the material density of $427.30 \mathrm{~kg} / \mathrm{m}^{3} \pm 19.30 \mathrm{~kg} / \mathrm{m}^{3}$.

Table 5. Compressive Strength Testing Condition and Results

\begin{tabular}{|c|c|c|c|c|c|c|c|c|}
\hline No. & $\begin{array}{c}\text { Diameter } \\
(\mathbf{c m}) \\
\end{array}$ & $\begin{array}{r}\text { Height } \\
(\mathrm{cm}) \\
\end{array}$ & $\begin{array}{l}\text { Area } \\
\left(\mathrm{cm}^{2}\right) \\
\end{array}$ & $\begin{array}{c}\text { Weight } \\
(\mathrm{kg}) \\
\end{array}$ & $\begin{array}{l}\text { Density } \\
\left(\mathrm{kg} / \mathrm{m}^{3}\right)\end{array}$ & $\begin{array}{c}\text { Ultimate } \\
\text { Load (kg) }\end{array}$ & $\begin{array}{c}\text { Ultimate } \\
\text { Stress (ksc.) }\end{array}$ & Remarks \\
\hline 1 & 15.73 & 31.50 & 194.33 & 2.61 & 426.37 & 2,048 & 10.74 & $\begin{array}{l}\text { Mixing } \\
\text { Ratio }\end{array}$ \\
\hline 2 & 15.58 & 30.20 & 190.64 & 2.59 & 449.86 & 2,173 & 11.18 & \\
\hline 3 & 15.62 & 31.40 & 191.50 & 2.74 & 455.67 & 2,259 & 11.80 & $\begin{array}{c}\text { Cement } 25 \% \\
\text { Water } 6 \%\end{array}$ \\
\hline Avg. & 15.64 & 31.03 & 192.16 & 2.65 & 443.97 & 2160 & 11.24 & Foam 69\% \\
\hline STD & 0.063 & 0.59 & 1.58 & 0.066 & 12.67 & 86.63 & 0.43 & (by volume) \\
\hline
\end{tabular}

\section{Tensile Strength Test Result of The Connecting Joint}

This research tests the tensile strength of the connecting joints because they are connected to other floating platforms. These connecting joints are responsible for the forces generated by the tides and water waves caused by the movement of small boats in the canal. The wave force is calculated from the wavelength of a small boat movement with an average wavelength of approximately 3.6 meters. The calculation of the moving wave speed is performed on a floating platform with a cross-sectional area equivalent to $1.2 \mathrm{~m}^{2}$, considering the speed of the waves in deep water, since the depth is greater than 0.5 times the wavelength[18]. We calculate the wave speed equal to $2.37 \mathrm{~m} / \mathrm{s}$ and then calculate the force acting on the floating platform using a 
variable formula: water density, wave speed, and cross-sectional area. The value of the force acting on the floating platform is 3,370 N[19]. Based on the results of the calculation of the wave force on the floating platform, it was used as a condition for analyzing and testing the strength of the floating platform connecting joints. In this design, the factor of safety allowance is 4, because the loading and environmental conditions are difficult to estimate[20], so the force that floating platform connecting joint can hold is $13,480 \mathrm{~N}$, or approximately $1,375 \mathrm{~kg}$. The joints must withstand a minimum of $1,400 \mathrm{~kg}$ according to the application requirements. The connecting joints have been designed to have the characteristics and dimensions as shown in Figure 6 and tested by pulling the connecting joint until the damage deformation is achieved. The results of the tensile strength testing of the connecting joints as shown in Table 6 . The ultimate load for the connecting joint was about $1,564 \mathrm{~kg}$.
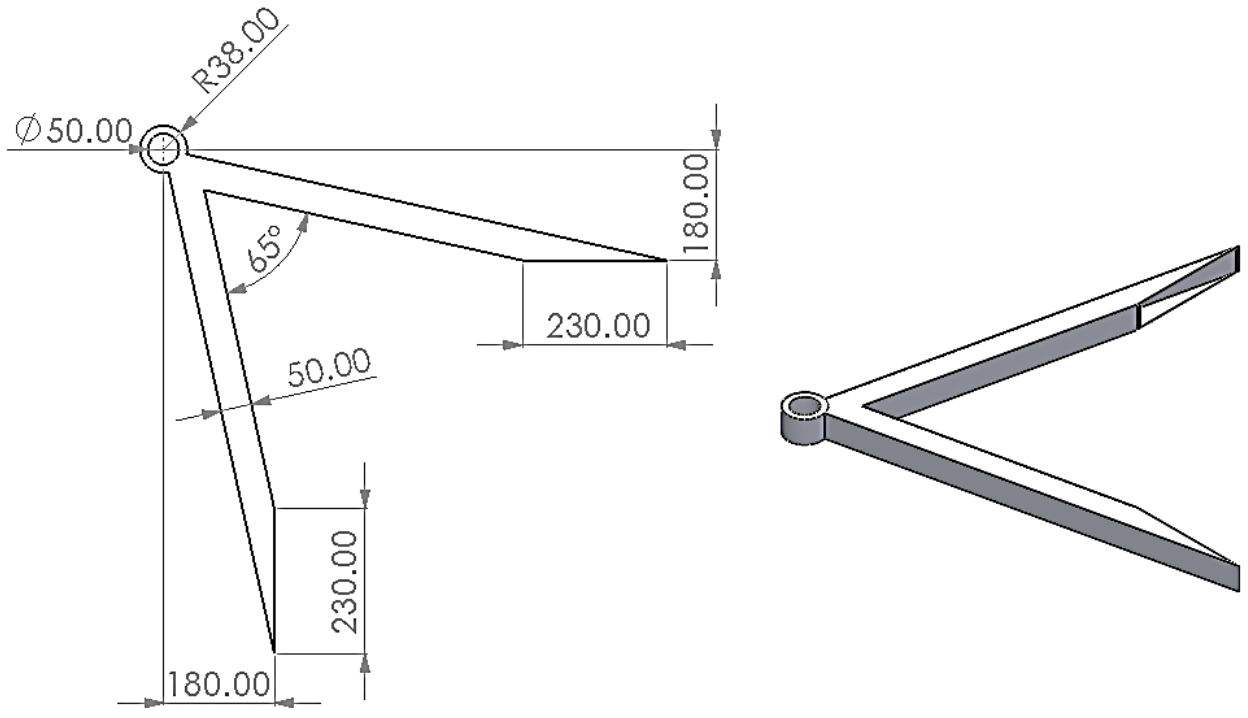

Figure 6. Characteristics and dimensions of connecting joint

Table 6. Tensile Strength Testing Result of Connecting Joint

\begin{tabular}{cc}
\hline Specimen & Ultimate Load testing Result (kg.) \\
\hline 1 & 1,522 \\
2 & 1,692 \\
3 & 1,478 \\
Average & 1,564 \\
\hline
\end{tabular}

\section{Compressive Test of The Foam-cement Floating Platform}

The compressive strength testing of the foam- cement floating platform consists of steel structures and foam cement. The test was performed by pressing the distributed force on the cross-sectional area of the floating platform by using a steel plate on top of the floating platform for testing, as shown in Figure 7. 


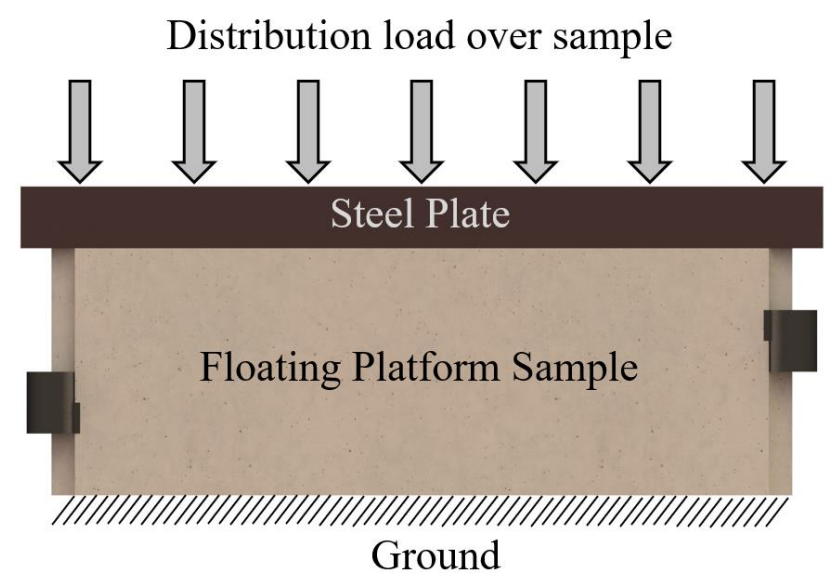

Figure 7. Method of floating platform compressive test

The compressive strength testing of the floating platform was performed until the deformation displacement of the floating platform reaches to $1 \mathrm{~mm}$. The results of the compressive strength test are shown in Table 7, which shows the data respectively from the minimum weight to the maximum weight of the foam cement floating platform. The low weight sample means that the foam proportion of the composite material was high, the density is low, so the value of the compressive stress test was similarly low. The compressive stress was 543.33 $\mathrm{kg} / \mathrm{m}^{2}$ with maximum vertical deformation of samples of $1 \mathrm{~mm}$.

Table 7. Compressive Strength and Deformation Testing Result of Floating Platform

\begin{tabular}{lcccc}
\multicolumn{1}{c}{ Item } & Sample-1 & Sample-2 & Sample-3 & Average \\
\hline $\begin{array}{l}\text { Weight of cement foam floating platform } \\
(\mathrm{kg})\end{array}$ & 847 & 865 & 872 & 861.33 \\
Weight of steel plate $(\mathrm{kg})$ & 385 & 385 & 385 & 385 \\
Distribution load over sample $(\mathrm{kg})$ & 1,542 & 1,579 & 1,592 & 1,571 \\
Projected top surface area of sample $\left(\mathrm{m}^{2}\right)$ & 3.6 & 3.6 & 3.6 & 3.6 \\
Compressive stress $\left(\mathrm{kg} / \mathrm{m}^{2}\right)$ & 535.28 & 545.56 & 549.17 & 543.33 \\
Max. vertical deformation of sample $(\mathrm{mm})$ & 1.0 & 1.0 & 1.0 & 1.0 \\
\hline
\end{tabular}

\section{Simulation Results}

Connecting Joint Strength Simulation Analysis Result

The 3D model and solid element, according to the data in section 2.5.1, are performed to analyze the strength of the connecting joint using the FEA method by determining the value of the force or weight used in the actual testing result in the Table 6 . The maximum stress from the analysis 
was greater than the yield strength of structural steel materials as shown in Table 1. From strength analysis, the load was $15,342 \mathrm{~N}$. and the analysis results as shown in Figure 8 . The stress concentration occurs near the circle ring in the expanded picture so maybe fillet or chamfer can be added to distribute the stresses for the better design
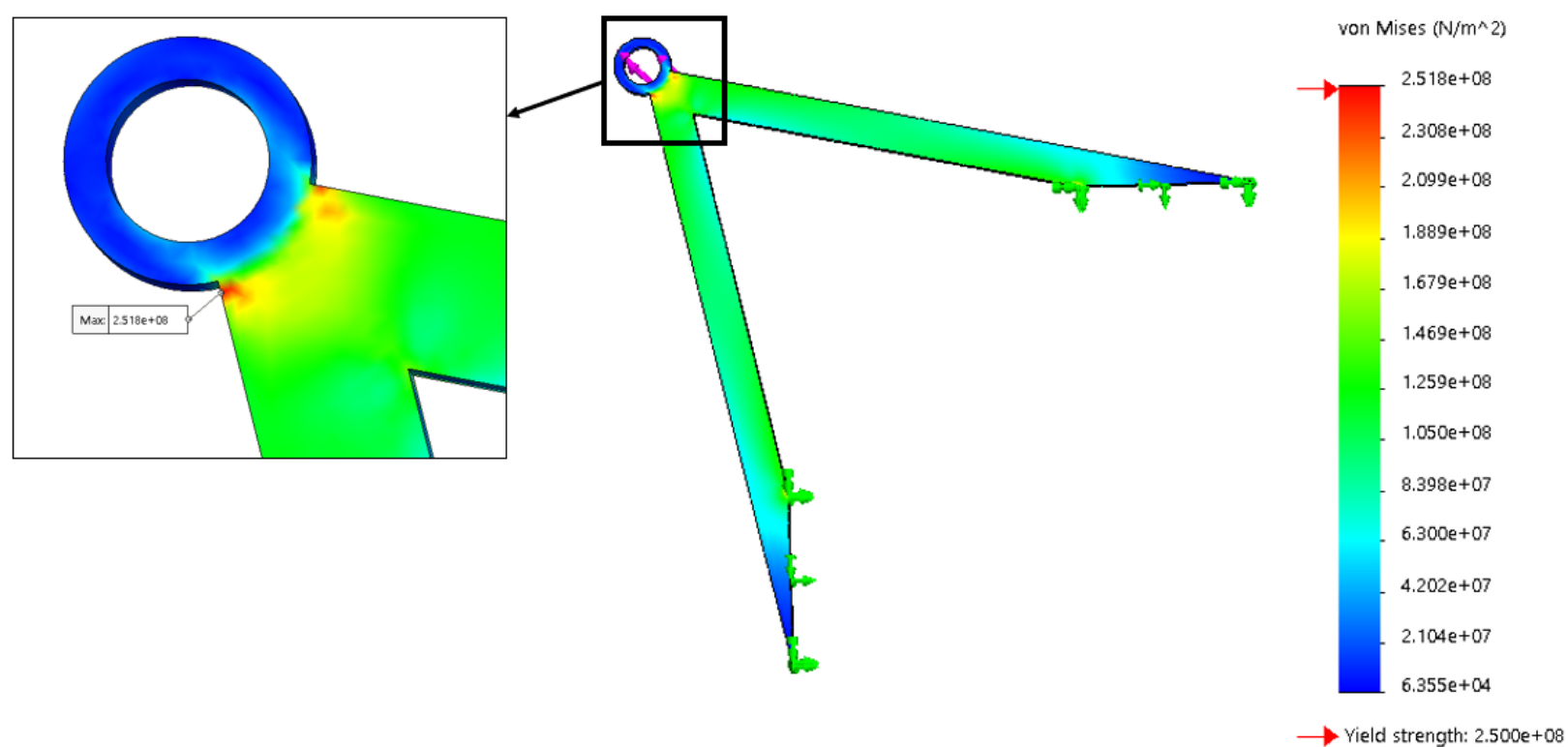

Figure 8 . The maximum stress of connecting joint simulation results

The results of analysis by FEM showed that the maximum stress occurred at $252 \mathrm{MPa}$, which was greater than the yield strength of the steel structure, which was about $250 \mathrm{MPa}$. The analysis showed that the specifying of the loading force value from the actual test makes the results of the analysis related to cause the deformation as the maximum stress was greater than the yield strength of the structural steel. From the values of the distributed forces in the finite element analysis, compared with the average values of the distributed forces from the actual test results, the error was $0.451 \%$. Based on the actual test results, the first damage location was at the seam between the circular ring and the triangle steel area, which was close to the stress concentration area of the analysis result as illustrated in Figure 8.

\section{Compressive Strength and Deformation Analysis Result of Floating Platform}

This research analyzed the deformation of the cement foam floating platform by particularizing the average distribution load from the actual test at $1,956 \mathrm{~kg}$. From the actual test result, the deformation displacement was $1 \mathrm{~mm}$. From the Solidworks simulation program, the maximum deformation displacement was $1.072 \mathrm{~mm}$ representing a 7\% tolerance compared to the actual test in Table 7. The simulation analyses distribution force loading for the collapse displacement to compare with the actual test. In this analysis, there was a fairly uniform distribution of forces and stresses to support the distribution forces. The Floating platform compressive stress simulation results are shown in Figure 9. 


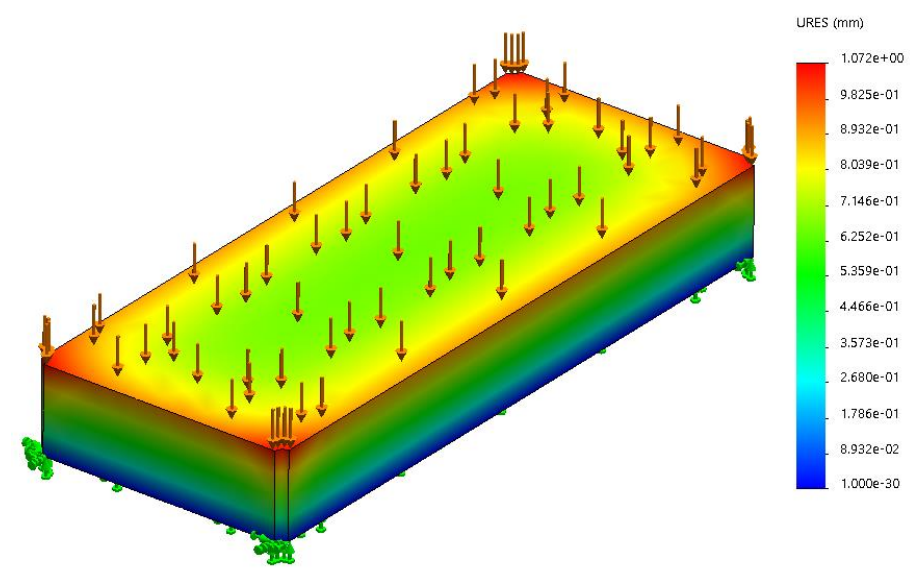

Figure 9. Floating platform compressive stress simulation results.

\section{Floating Platform Steel Structure Stress Analysis Result}

The above actual testing and analysis results show that the position of the steel structure that has the highest stress value is the position on the part of the connecting joint. Because the testing and analysis results were tested and analyzed according to the requirements of the floating platform design. The results show that the floating platform was strong enough to meet the design requirements. This research has designed the steel structure of this floating platform to be strong enough. Results from the strength analysis was comparable with the actual test. The comparison of the analysis results with the actual test results was reliable and acceptable. The design requirements for the floating platform to be able to operate safely must have a factor of safety not less than 3. M Pricop stated that factors of safety in offshore structures design according to environmental loads suitable for designing structural types as semisubmersible platform, the factor of safety should be at least 3 [21]. Additionally, R Maria reported that the general recommendation for application usage in the factor of safety consideration if the structure used with materials where properties are not reliable and the environmental loading are not severe, the factor of safety should be at least 3[21]. After designing the steel structure and analyzing the strength of the steel structure, the analysis results are shown in Figure 10.

Figure 10 shows that the analysis of the steel structure by determining the value of the tension force on the connecting joint of the floating platform on both sides. By specifying the value of the tensile force $1400 \mathrm{~kg}$ per side and holding the other 2 connecting joints, the results of strength analysis of the steel structure had the maximum stress of $72.2 \mathrm{MPa}$. This yielded the factor of safety of 3.46 which was more than the factor of safety according to the design requirements. This design has stress concentration points that are mostly located on the corner with less than or equal to a right angle which can add parts to support the force in that area to distribute the stress. From the design and analysis of the strength and properties of the floating platform for protection against the force of waves causing the erosion of river banks and canals. It can be seen that what has been calculated and designed is important for the strength of the floating platform. The steel structure and the floating platform connecting joint sufficiently to withstand the wave force of the movement of boats in rivers and canals. 

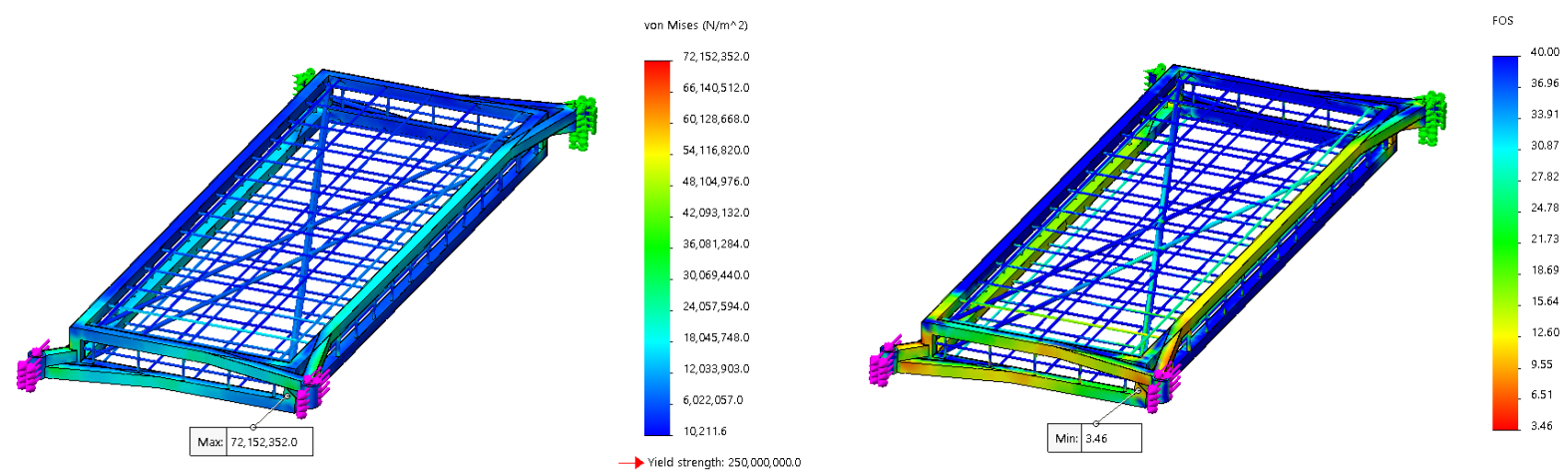

Figure 10. Steel structure simulation results.

\section{Conclusions}

This research designed and fabricated a concrete-reinforced floating platform with mechanical simulation. The floating platform consists of three important parts: (1) steel structure, (2) foamcement material, and (3) connecting joints. Conclusion can be made as follows:

1. The cement foam floating platform is designed to be $1.2 \mathrm{~m}$ in width, $3 \mathrm{~m}$ in length and $0.4 \mathrm{~m}$ in thickness. the cement used in this research is resistant to corrosion of sulfate and chloride from saltwater mixed with foam with a density is approximately $12 \mathrm{~kg} / \mathrm{m}^{3}$ so that the floating platform can float $60 \%$ or above the water surface, approximately 0.16 meters

2. From compressive test of foam cement material, the maximum compression stress was about $1,951 \mathrm{~kg} \pm 266.59 \mathrm{~kg}$ for the material density of $427.30 \mathrm{~kg} / \mathrm{m}^{3} \pm 19.30 \mathrm{~kg} / \mathrm{m}^{3}$. From tensile strength test of joint material, the ultimate load for the connecting joint was about 1,564 $\mathrm{kg}$. After assemble the floating platform product, the compressive stress was $543.33 \mathrm{~kg} / \mathrm{m}^{2}$ with maximum vertical deformation of samples of $1 \mathrm{~mm}$ under the distribution load of 1,571 over the samples.

3. From simulation results of the floating platform using the data from material testing, the designed floating platform had a safety factor 3.46 which was higher than the design criteria of 3 .

\section{Acknowledgements}

This research received funding from Athens Production Co, Ltd. P. Sarabhorn received scholarship the Faculty of Engineering, Kasetsart University.

\section{References}

[1] T. Van Man, H. Van Thang, and P. Truong, "VST in river and canal bank stabilisation in central Vietnam : successes and failures ten years later," Paper presented at Fifth International Vetiver Conference, Lucknow, India, 2011. 
[2] S. Semmad, Riverbank Retreat and Erosion Protection of the U-Tapao River in Songkhla Province, Prince of Songkhla University, Songkhla, Thailand, 2017.

[3] Malawaik, Problem and Solution Approaches for Failure of River Banks of Huikaen River, Thesis (PhD), Suranaree University of Technology, Nakhon Ratchasima, Thailand, 2011.

[4] S. Iyengar, "Environmental damage to land resource. need to improve land use data base," Economic and Political Weekly, Vol. 38, No. 34, pp. 3596-3604, 2003.

[5] A. Bonham, "The management of wave-spending vegetation as bank protection against boat wash," Landscape Planning, Vol. 10, No. 1, pp. 15-30, 1983.

[6] H. King, "The use of groynes for riverbank erosion protection," Paper presented at Stormwater and Flood management Conference, University of Stellenbosch, Stellenbosch, Western Cape, South Africa, 2009.

[7] S. Sharapov, Floating Platform with Non-uniformly Distributed Load and Method of Construction Thereof, U.S. patent No. 7,575,397, 2009.

[8] W.W. Sluys, Concrete Marine Float and Method of Fabricating, U.S. patent No. 4,265,193, 1981.

[9] G. Cuomo, W. Allsop, T. Bruce, and J. Pearson, "Breaking wave loads at vertical seawalls and breakwaters," Coastal Engineering, Vol. 57, No. 4, pp. 424-439, 2010.

[10] M. Kirkgöz, "Breaking wave impact on vertical and sloping coastal structures," Ocean Engineering, Vol. 22, No. 1, pp. 35-48, 1995.

[11] H.E. Dempster, Concrete Floating Structure, U.S. patent No. 3,490,407, 1970.

[12] R.V. Petrova, Introduction to Static Analysis Using Solid Works Simulation, CRC Press, Boca Raton, Florida, United States, 2014.

[13] P.E. Smith, "Design and specification of marine concrete structures," In Marine Concrete Structures, Mark G. Alexander, ed.: Elsevier, Amsterdam, Netherlands, pp. 65-114, 2016.

[14] M. Thomas, "The durability of concrete for marine construction: Materials and properties," In Marine Concrete Structures, M.G. Alexander, ed.: Elsevier, Amsterdam, Netherlands, pp. 151-170, 2016.

[15] N. Jennings, Floating Low Density Concrete Barrier, U.S. Patent No. 6,994,048, 2006.

[16] S. Kroviakov, and A. Mishutn, "Production technology of modified expanded clay lightweight concrete for floating structures," The Scientific Journal of Cihan UniversitySulaimanyia, Vol. 1, No. 4, pp.02-10, 2017. doi: 10.25098/1.2.2211

[17] Y. Fang, R. Wang, E. Pang, and Y. Zhou, "Relationship between compressive strength and air-void structure of foamed cement-fly ash concrete," Guisuanyan Xuebao (Journal of the Chinese Ceramic Society), Vol. 38, No. 4, pp. 621-626, 2010.

[18] H.V. Thurman, and A.P. Trujillo, Essentials of Oceanography: Waves and Water Dynamics, $7^{\text {th }}$ Edition, Prentice Hall PTR, United States, 2001.

[19] A. Techet, "2.016 Hydrodynamics," MIT Department of Mechanical Engineering, Lecture Notes, August 2005 [PDF]. Retrieved from http://ocw. mit. edu/courses/mechanicalengineering/2-016-hydrodynamic-13-012-fall-2005/readings/2005reading6. pdf

[20] M. Rutheravan, Summary of Safety Criteria in Design, University Malaysia Pahang, Pekan, Pahang, Malaysia, 2016.

[21] M. Pricop, V. Oncica, and I.C. Scurtu, "Factor of safety in offshore structures design according to environmental loads," Scientific Bulletin of Naval Academy, Vol. 16, No. 2, pp. 152157, 2013. 